Original Research Article

\title{
Pattern of drug use among the geriatric patients: a prospective, observational and hospital based study
}

\author{
Ramya Jonnalagadda ${ }^{1} *$, Ajay Kumar $^{2}$
}

${ }^{1}$ Department of Pharmacology, Katuri Medical College, Guntur, Andhra Pradesh, India

${ }^{2}$ Department of ENT, Sri

Venkateswara Medical College, Tirupati, Andhra Pradesh, India

Received: 10 October 2019

Revised: 12 November 2019

Accepted: 14 November 2019

*Correspondence to:

Dr. Ramya Jonnalagadda, Email: ramyajonnalagadda77@ gmail.com

Copyright: (C) the author(s), publisher and licensee Medip Academy. This is an openaccess article distributed under the terms of the Creative Commons Attribution NonCommercial License, which permits unrestricted noncommercial use, distribution, and reproduction in any medium, provided the original work is properly cited.

\begin{abstract}
Background: The world's population continues to grow at an unprecedented rate. With the advances in medical therapeutics have contributed to health gains and increase in life expectancy. So strategies to improve prescribing are essential so as to ensure that the medications available to manage concurrent disease states are prescribed appropriately. This study is undertaken to identify patterns of drug use in treating elderly patients and assessment of polypharmacy among the geriatric age group.

Methods: The study was approved by institutional ethics committee of Rangaraya Medical College, Kakinada. The study was conducted as a hospital based study in different departments in Government General Hospital during period from January 2016 to December 2016 at Government General Hospital with a total of 549 patients among outpatient and inpatients.

Results: Polypharmacy is unfortunately very common in India and some other countries. In the present study average number of drugs prescribed per patient was 4.66.

Conclusions: With ever increasing therapeutic options, escalating proportions of older people worldwide, the prescription pattern among them matters a lot. Also as this group of patients are vulnerable, taking necessary care and reviewing the past drug history will have a major role and increase the betterment of the geriatric age group.
\end{abstract}

Keywords: Geriatric, Drug utilization, Polypharmacy

\section{INTRODUCTION}

The elderly population is increasing rapidly worldwide. These are a special group of people to be discussed because they come with an array of challenges such as co morbidities, disabilities and frailty. ${ }^{1}$ Strategies to improve prescribing are essential so as to ensure that the medications available to manage concurrent disease states are prescribed appropriately. Polypharmacy is the use of more medications than are medically necessary. ${ }^{2}$ This study is undertaken to identify patterns of drug use in treating elderly patients and assessment of polypharmacy among the geriatric age group

\section{METHODS}

The study was approved by institutional ethics committee of Rangaraya Medical College, Kakinada. The study was conducted as a hospital based study in the Department of medicine, surgery, psychiatry, ophthalmology, orthopaedics, gynaecology, skin, antiretroviral therapy, chest and tuberculosis, ENT in Government General Hospital during period from January 2016 to December 2016 at Government General Hospital with a total of 549 patients among outpatient and inpatients. To identify patterns of drug use prescriptions were collected from the respective departments. 


\section{Inclusion criteria}

Both male and female above 65 years of age of inpatients and outpatient patients were included in the study.

\section{Exclusion criteria}

Patients attending casualty radiotherapy and cancer patients, patients on herbal preparations, absconding patients and patients on ventilators were excluded from the study.

From the prescriptions number of drugs for each prescription is tabulated. The analysis is done with SPSS 16 software and Microsoft Excel is used for calculating results.

\section{RESULTS}

The percentages of males are more compared to that of females in the present study.

Table 1: Gender distribution.

\begin{tabular}{|lll|}
\hline Gender & $\begin{array}{l}\text { Number of } \\
\text { patients }\end{array}$ & $\%$ \\
\hline Male & 284 & 51.7 \\
\hline Female & 265 & 48.2 \\
\hline
\end{tabular}

Maximum number of patients is included in the age group of 65 to 74 years followed by 75 to 84 and the least with age group of greater than 95 .

Table 2: Age distribution among patients.

\begin{tabular}{|l|l|l|}
\hline $\begin{array}{l}\text { Age groups (in } \\
\text { years) }\end{array}$ & $\begin{array}{l}\text { No. of } \\
\text { patients }\end{array}$ & $\%$ \\
\hline $\mathbf{6 5 - 7 4}$ & 336 & 61.20 \\
\hline $\mathbf{7 5 - 8 4}$ & 123 & 22.40 \\
\hline $\mathbf{8 5 - 9 4}$ & 82 & 14.93 \\
\hline$>\mathbf{9 5}$ & 8 & 1.45 \\
\hline
\end{tabular}

Table 3: Prescribed drugs.

\begin{tabular}{|llll|}
\hline S. & Drugs & $\begin{array}{l}\text { Total } \\
(\mathbf{n = 5 4 9})\end{array}$ & $\%$ \\
\hline No. & Anti-ulcer and antacids & 466 & 84.88 \\
\hline $\mathbf{2}$ & Supplements & 449 & 81.78 \\
\hline $\mathbf{3}$ & Anti-microbial & 402 & 73.22 \\
\hline $\mathbf{4}$ & Autocoids & 299 & 54.46 \\
\hline $\mathbf{5}$ & Anti-hypertensives & 237 & 43.16 \\
\hline
\end{tabular}

Most commonly prescribed drugs in the study are anti ulcers and antacids followed by vitamin supplements and antibiotics.

Average number of drugs per prescription is 4.66 .
Table 4: Number of drugs per prescription.

\begin{tabular}{|lll|}
\hline $\begin{array}{l}\text { No. of drugs per } \\
\text { prescriptions }\end{array}$ & $\begin{array}{l}\text { No. of patients } \\
(\mathbf{n = 5 4 9 )}\end{array}$ & $\%$ \\
\hline $\mathbf{1}$ & 0 & 0 \\
\hline $\mathbf{2}$ & 28 & 5.10 \\
\hline $\mathbf{3}$ & 110 & 20.03 \\
\hline $\mathbf{4}$ & 123 & 22.40 \\
\hline $\mathbf{5}$ & 123 & 22.40 \\
\hline $\mathbf{6}$ & 100 & 18.21 \\
\hline $\mathbf{7}$ & 54 & 9.83 \\
\hline $\mathbf{8}$ & 11 & 2.00 \\
\hline
\end{tabular}

Table 5: Number of drugs in all the prescriptions prescribed by generic names.

\begin{tabular}{|llll|}
\hline S. No. & Description & n=549 & $\%$ \\
\hline 1 & $\begin{array}{l}\text { Drugs prescribed by } \\
\text { generic name }\end{array}$ & 338 & 61.56 \\
\hline
\end{tabular}

Maximum number of patients prescribed is 4-5 drugs followed by three.

\section{DISCUSSION}

There is rapid ageing of population throughout the world. Drug utilization studies are a tool for assessing the prescribing, dispensing, and distribution of drugs. According to the 66th World Health assembly organized by the WHO at Hague in May 2013, there would be an increase from $11 \%$ in 2000 to $22 \%$ in 2050 in the proportion of people aged over 60 years ${ }^{3}$. In our study the percentage of male patients $(51.7 \%)$ was only marginally higher than female patients $(48.2 \%)$, with male to female ratio 1: 0.93 .

Polypharmacy is unfortunately very common in India and some other countries. In the present study average number of drugs prescribed per patient was 4.66. This is very less compared to Goudanavar et al where the average number of drugs per prescription was 8.5 which is 4 times more than our study. ${ }^{4}$ Another study by Kohle et al has much less average number of drugs 5 . The number of patients who were prescribed 5 drugs or more than 5 that is polypharmacy are 288 in number.

Polypharmacy results in increased cost of treatment, which may lead to non-adherence by patients. It also increases the risk of drug interactions. The consequences of polypharmacy lead to increased healthcare costs by increasing the cost of medications and also the outcome with the drug interactions. This is proved in a study done in Sweden that those taking 5 or more medications had a $6.2 \%$ increase in prescription drug expenditure and those taking 10 or more medications had a $7.3 \%$ increase. $^{6}$ Cognitive impairment, delirium and dementia, has been associated with polypharmacy. A study in hospitalized older adults reported that the number of medications was a risk factor for delirium. ${ }^{6}$ 
Polypharmacy has also been reported to affect a patient's nutritional status. A prospective cohort study found that $50 \%$ of those taking 10 or more medications were found to be malnourished or at risk of malnourishment. ${ }^{7}$ Urinary incontinence is yet another problem that is associated with the use of multiple medications. In a populationbased, longitudinal study of women aged 70 years and older, polypharmacy was associated with an increased risk of lower urinary tract symptoms. ${ }^{8}$

\section{CONCLUSION}

The study is focused on improving treatment interventions in terms of safety, efficacy and patient compliance among geriatric patients. The average number of drugs is 4.66 , hence in the present study polypharmacy is not seen. Among the groups of drugs more commonly prescribed are anti-ulcer and antacids followed by supplements and then the anti-microbial. So I conclude that as this group of patients are vulnerable, taking necessary care and reviewing the past drug history will have a major role and increase the betterment of the geriatric age group.

Funding: No funding sources Conflict of interest: None declared

Ethical approval: The study was approved by the Institutional Ethics Committee

\section{REFERENCES}

1. Jhaveri BN, Patel TK, Barvaliya MJ, Tripathi CB. Drug utilization pattern and pharmacoeconomic analysis in geriatric medical in-patients of a tertiary care hospital of India. J Pharmacol Pharmacotherapeutic. 2014;5(1):15.
2. Maher RL, Hanlon J, Hajjar ER. Clinical consequences of polypharmacy in elderly. Expert opinion on drug safety. 2014;13(1):57-65.

3. Sultan HA, Sayeg KY, Mohammad AV, Hussain SM, Sumaily JMY, Agarwal M, et al. Prescribing pattern of drugs in the geriatric patients in Jazan Province, KSA. Pharmacy Pharmacol Intl J. 2015;2(1):00013.

4. Goudanavar P, Keerthi Y, John SE, Jacob J, Krishna MR. A prospective study on medication prescribing pattern for geriatric patients in a tertiary care teaching hospital. Asian J Biomed Pharm Sci. 2016;6(56).

5. Sindhuri NJ, Wagle L, Joy DK, Manikanata BD, Mathew A. Assessment of drug use in geriatric patients at rural tertiary care teaching hospital in South India. 2016;5(7):1194-201.

6. Hovstadius B, Petersson G. The impact of increasing polypharmacy on prescribed drug expenditure- a register-based study in Sweden 2005-2009. Health Policy. 2013;109(2):166-74.

7. Jyrkka J, Enlund H, Lavikainen P, Sulkava R, Hartikainen S. Association of polypharmacy with nutritional status, functional ability and cognitive capacity over a three-year period in an elderly population. Pharmacoepidemiol Drug Saf. 2011;20(5):514-22.

8. Nuotio M, Jylha M, Luukkaala T, Tammela TL. Health problems associated with lower urinary tract symptoms in older women: a population-based survey. Scandinav J Primary Health Care. 2005;23(4):209-14.

Cite this article as: Jonnalagadda R, Kumar A. Pattern of drug use among the geriatric patients- a prospective, observational and hospital based study. Int J Basic Clin Pharmacol 2019;8:2721-3. 